\title{
A tribute to Professor David J.P. Barker (FRS CBE) - 29 June 1938-27 August 2013
}

\author{
Delivered by Caroline Fall at the 8th World Congress on Developmental Origins of Health and Disease, Singapore, 20 November 2013.
}

We would not be sitting here if it were not for David Barker (Fig. 1). We would not have the DOHaD Society. We would not have the 8th World Congress. Embryologists would not be talking to diabetologists or listening to talks on influencing public health policy. Those of us who are building our careers in lifecourse epidemiology, developmental pathways, maternal nutrition or foetal physiology would probably not be doing that, at least not in such large numbers; most of us would be doing something else. He has literally changed the lives of many people in this room. Without David's work, mothers and babies would not be on the World Health Assembly NCD agenda and we would not be talking about 'the first 1000 days'.

I'm not saying that he did all this himself. The crucial things that he did were to realize that every system of the body is permanently affected by the environment during early development, to envisage the huge implications of this, to devote the last 25 years of his life to persuading the scientific world about it, to bring together the multiple disciplines represented here in order to build the evidence, and to include developing countries at the centre of the discussions right from the beginning. The achievement of his life was to inspire the whole new specialty in science and global movement that is $\mathrm{DOHaD}$.

What was it about David that led him to this amazing achievement? First, conviction: conviction that the links he saw between early life and adult disease were real. We tend to think this all started when he linked cardiovascular mortality to historic levels of infant mortality or to birthweight. But his certainty came from at least two decades of his earlier work. If you read his early papers on intelligence, on appendicitis, thyroid disease and Paget's disease, he repeatedly found evidence of roots in early life. Others had started to see these links too, like Forsdahl in Norway, and Ravelli from the Dutch Hunger Winter Group, but David had the conviction and vision to grasp the idea and run with it. Second, there was his extraordinary single-mindedness and determination. It's hard to recall it now, but his ideas were greeted with scepticism, which is absolutely right and proper, but also with hostility and ridicule. He had a fighting personality, a pugnacious personality. It sometimes got him into trouble and it could be divisive, but I believe that if he had not worked and argued and fought for his ideas as hard as he did, they would not have seen the light of day. Third, he was at heart a biologist, dating right back to an inspirational teacher at school. His comfort with biology meant that at an early stage he linked up with basic scientists. This slide shows some of those people (Fig. 2), the 'founding fathers' of $\mathrm{DOHaD}$. When the evidence for programming in humans remained so shadowy and open to criticism, he was able to harness incontrovertible evidence from animal studies, start to understand the mechanisms and see the importance of nutrition in the $\mathrm{DOHaD}$ story.

Fourth, he was a brilliant thinker, had a unique way of looking at data and an amazing memory for data. The only way I can express it is to say that he 'could see data in three if not four dimensions'. His mind could synthesize data coming from different sources and envisage pathways across time in a way that no one
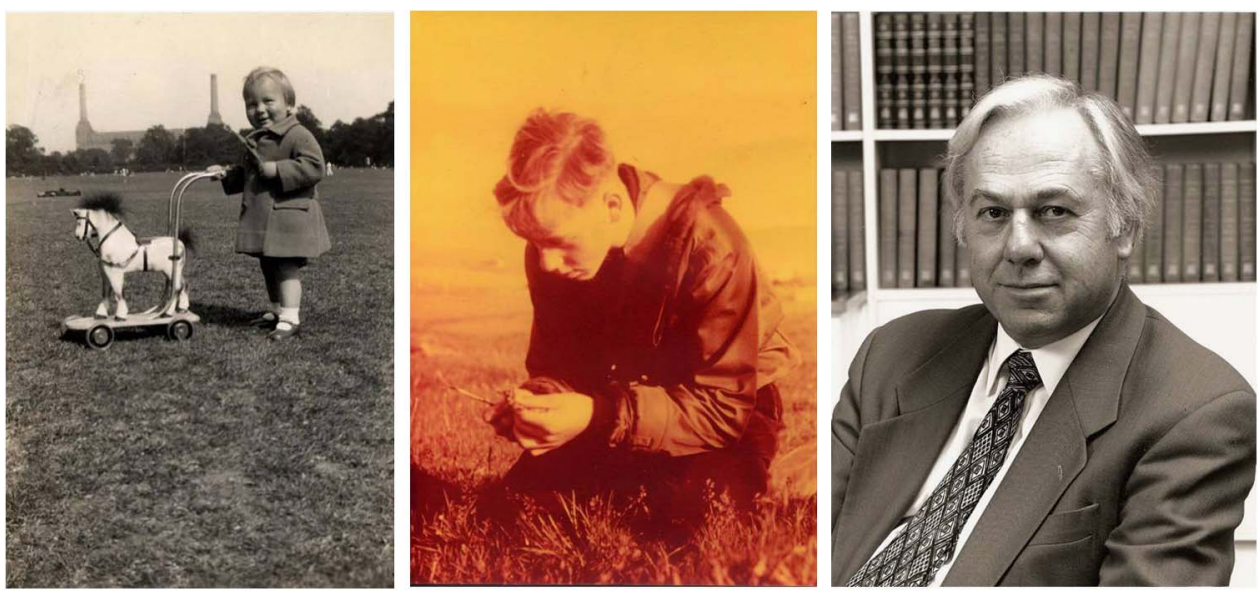

Fig. 1. A lifecourse view of David Barker: as a toddler in London with Battersea Power Station in the background; as a teenager collecting plants as part of a National History Museum project on the Icelandic island of Grimsey; and as Director of the MRC Environmental Epidemiology Unit, University of Southampton. 


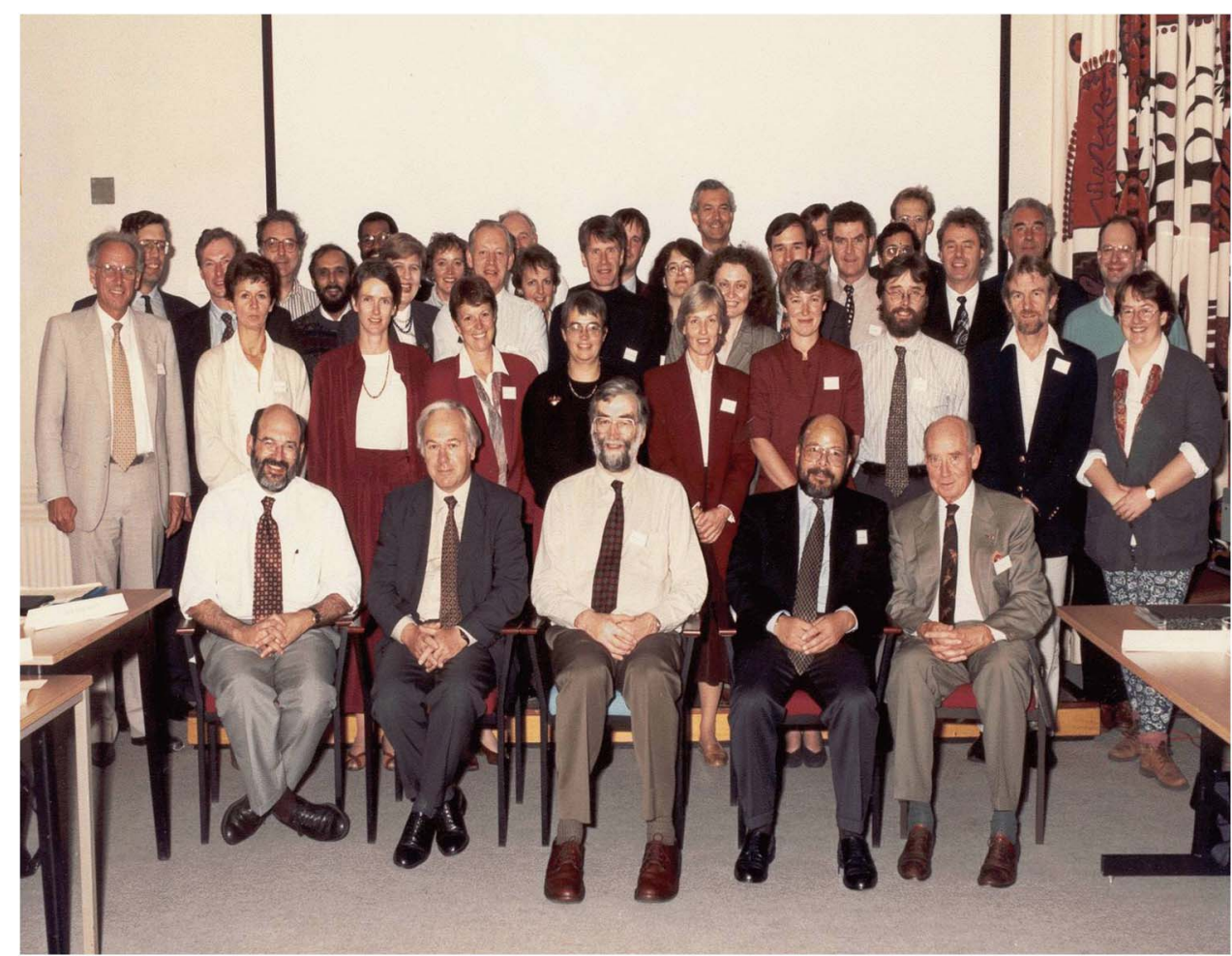

Fig. 2. An early meeting (approximately 1994) of the epidemiologists, clinicians and basic scientists who went on to found the International DOHaD Society.

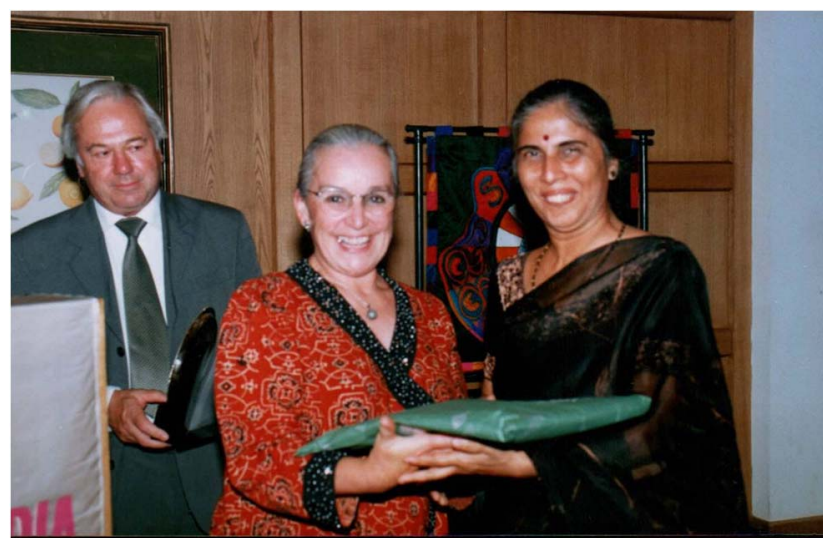

Fig. 3. Jan Barker accompanying David at a ceremony to celebrate the founding of Sneha-India, for which Jan embroidered a banner, just visible behind her.

else could do. Finally, he was a wonderful communicator, an exceptional speaker and writer, an inspiring teacher not only to us in Southampton, but also to many young scientists around the world, for whom he was always generous with his time.

In addition, David had two secret weapons in his life. One was his wife Jan, who was not only a constant support to David throughout the punishing work schedule that he imposed upon himself, but created the environment around him in which he could focus on that work, in the process sacrificing many of her own interests (Fig. 3). She was a huge help to his work because of her warm, open and informal personality, which complemented David's rather private and reserved personality, and that broke down many barriers. Jan's embroidery brought alive many of David's ideas about foetal physiology, and embellished the covers of three of David's books on $\mathrm{DOHaD}$.

David's other secret weapon was his sense of humour and quick wit. Stories, jokes, anecdotes, leg-pulling and mickeytaking were an integral part of working with David. He was simply enormous fun to be with. One of his and our favourite activities was to have a whole day stretching ahead of us, to settle down in a group with one of the statisticians to analyze data and write a paper. You would hear David ('Prof) coming down the corridor, from the jingling of coins in his pockets. He'd start by throwing a few gentle insults at the statistician present. Soon, a colleague would appear with a cup of coffee for him, in his trademark brown mug. By way of thanks he would express to her his usual surprise that she was still here and hadn't been sacked yet! Then we'd get down to business, he armed only with a fountain pen. You knew it would be an intense day, in which raw data would get sorted out and transformed as if by magic into a decent manuscript, with amazing clarity and speed and attention to detail. That was his forte. And still there would always be time for anecdotes and general discussions about the meaning of life.

I did a lot of travelling with David and Jan because they went out of their way to support my work in India. He loved to be 

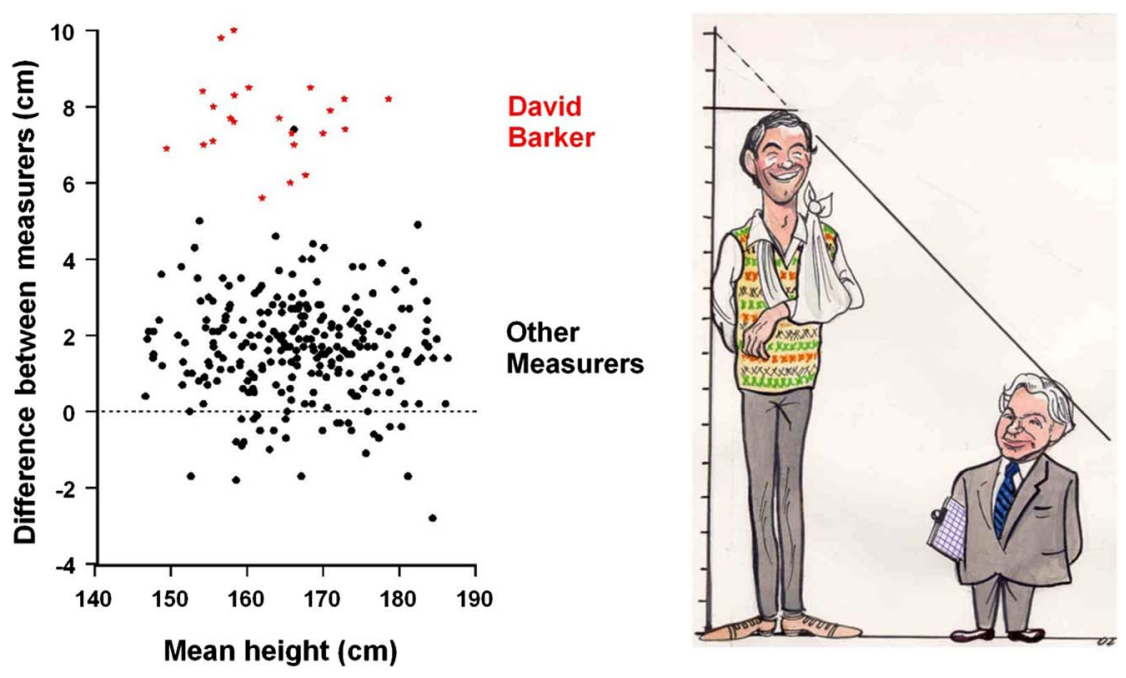

Fig. 4. A graph and cartoon shown by Clive Osmond at the 1992 Christmas Show in the MRC Environmental Epidemiology Unit to demonstrate David's shortcomings in human anthropometry.

'in the field', watching people and taking in the nuts and bolts of research. In India, this sometimes meant sitting cross-legged on the ground for long periods, a posture he wasn't really designed for, but which he managed because he was in his element. At the other end of the spectrum I often observed him playing the 'hotel game'. On arriving at a hotel, it was his standard procedure to reject every room that was offered to him, using more and more creative and implausible reasons, the aim being to get the best room in the place at no extra cost. He was completely shameless and extremely successful at this. 'How to get the best hotel room' was one of two papers that he always said he would write before he died, the other one being 'Assassination - an underused tool in epidemiology'.

He was very happy too to be at the receiving end of the joke, in fact he enjoyed it enormously. In the early days of the Preston Birth Cohort study, he volunteered to become a temporary fieldworker so that data collection wouldn't have to stop over the Christmas holiday. He always took it in good heart when statistician Clive Osmond pointed out to him that all the height data that he collected had to be repeated, because of a systematic difference in the data from the regular field team, for obvious reasons (Fig. 4).

David never stopped doing research. After retiring as Director of the MRC Epidemiology Unit in Southampton, he spent part of each year working in Portland with Kent Thornburg on the placenta and with Michelle Lampl at Emory University, on growth. He was fascinated by the two-way conversation between the reproductive tract and the earliest stages of the fertilized egg, the egg that was formed when the woman was herself in her mother's uterus, in conditions created by the nutritional history of the grandmother. He called this ' 100 years of nutritional flow'. He was convinced that when we understood how the placenta and foetus responded to this nutritional flow we would understand the mysterious rise and fall of numerous diseases.
David spent the weeks before he died working in Southampton, analyzing data and writing papers, especially with Clive, his long-time statistician colleague, and checking in with all of us on our work. I think we will always remember the conversations we had with him then. Although his death was sudden and to us far too early, it's good to remember that he was incredibly optimistic about $\mathrm{DOHaD}$, and felt that it had reached a point where it was unstoppable, and was beginning to realize its potential to have a huge impact. He thought there was so much left to do, and he clearly envisaged himself continuing to play a large part in that, but he also thought that the skills needed to take it forward, to translate it into action, to uncover the mechanisms, were not his skills, and that $\mathrm{DOHaD}$ now had the critical mass of people to achieve that work. He was even talking about easing back, taking more time to relax. Well, we all knew that he would never actually do that.

These are words that David used just a few weeks before he died at a function to celebrate the centenary of the MRC: 'The greatest gift we could give to the next generation is to improve the nutrition and growth of girls and young women. The world does not have to suffer from heart disease, osteoporosis or breast cancer. These are not mandated by the human genome. They barely existed a hundred years ago. They are unnecessary diseases. We could prevent them had we the will do so'.

The best way we can remember David is to continue that work. We were privileged to know such a witty, visionary and life-enhancing man. We will miss him greatly. I invite you join me in a round of applause for a remarkable man and a remarkable life.

C. H. D. Fall

MRC Lifecourse Epidemiology Unit, University of Southampton, UK Email: chdf@mrc.soton.ac.uk 